\title{
The relationship between technical performance indicators and running performance in elite Gaelic football
}

\author{
Shane Mangan \\ Technological University Dublin, shane.mangan@tudublin.ie \\ Martin Ryan \\ Technological University Dublin \\ Simon Devenney \\ Technological University Dublin, simon.devenney@tudublin.ie
}

See next page for additional authors

Follow this and additional works at: https://arrow.tudublin.ie/ittsciart

Part of the Sports Sciences Commons

\section{Recommended Citation \\ Shane Mangan, Martin Ryan, Simon Devenney, Aidan Shovlin, Jason McGahan, Shane Malone, Cian O'Neill, Con Burns \& Kieran Collins (2017) The relationship between technical performance indicators and running performance in elite Gaelic football, International Journal of Performance Analysis in Sport, 17:5, 706-720, DOI: 10.1080/24748668.2017.1387409}

This Article is brought to you for free and open access by the School of Science and Computing at ARROW@TU Dublin. It has been accepted for inclusion in Articles by an authorized administrator of ARROW@TU Dublin. For more information, please contact arrow.admin@tudublin.ie, aisling.coyne@tudublin.ie, gerard.connolly@tudublin.ie.

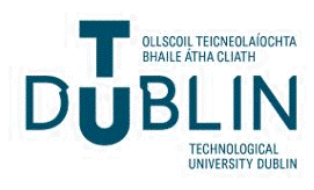




\section{Authors}

Shane Mangan, Martin Ryan, Simon Devenney, Aidan Shovlin, Jason McGahan, Shane Malone, Cian O'Neill, Con Burns, and Kieran Collins 


\section{International Journal of Performance Analysis in Sport}

\section{The relationship between technical performance indicators and running performance in elite Gaelic football}

Shane Mangan, Martin Ryan, Simon Devenney, Aidan Shovlin, Jason McGahan, Shane Malone, Cian O'Neill, Con Burns \& Kieran Collins

To cite this article: Shane Mangan, Martin Ryan, Simon Devenney, Aidan Shovlin, Jason McGahan, Shane Malone, Cian O'Neill, Con Burns \& Kieran Collins (2017) The relationship between technical performance indicators and running performance in elite Gaelic football, International Journal of Performance Analysis in Sport, 17:5, 706-720, DOI: 10.1080/24748668.2017.1387409

To link to this article: https://doi.org/10.1080/24748668.2017.1387409

Published online: 17 Oct 2017.

Submit your article to this journal $2 \pi$

Џll Article views: 1221

à

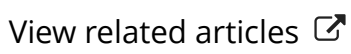

View Crossmark data $[\pi$

Citing articles: 6 View citing articles ¿ð 


\title{
The relationship between technical performance indicators and running performance in elite Gaelic football
}

\author{
Shane Mangan ${ }^{a}$, Martin Ryan ${ }^{a}$, Simon Devenney ${ }^{b}$, Aidan Shovlina , Jason McGahanc, \\ Shane Malone ${ }^{a}$, Cian O’Neillc, Con Burns ${ }^{c}$ and Kieran Collins ${ }^{a}$ (iD \\ ${ }^{a}$ Gaelic Sports Research Centre, Institute of Technology Tallaght, Dublin, Ireland; ${ }^{b} C e n t r e$ for Exercise and \\ Metabolic Science, Institute of Technology Tallaght, Dublin, Ireland; 'Department of Sport, Leisure and \\ Childhood Studies, Cork Institute of Technology, Cork, Ireland
}

\begin{abstract}
The aim of the current study was to assess whether technical performance relates to positional running demands of elite Gaelic football players. Over a period of three years (2014-2016), four elite Gaelic football teams were monitored using GPS technologies. Four hundred and thirty-two individual player samples were collected from 52 competitive matches. Video analysis software was used to code technical performance indicators in all games. Pearson's correlations were performed between all technical variables and total distance $(\mathrm{m})$ and high-speed distance $\left(\geq 17 \mathrm{~km} \mathrm{~h}^{-1}\right)$. Total ball in play time had small to medium effects ( $r=.233$ to $.390, p \geq 0.190$ ) on increasing the amount of total distance and high-speed distance run. Similarly, the percentage of short kick-outs taken by the opposition team and total opposition possession time had small to medium effects ( $r=.146-$ $.410, p \geq 0.202$ ) in increasing the amount of total distance and highspeed distance run. The number of fouls made in the middle third had the largest negative effect $(r=-.89$ to $-.325, p \geq 0.439)$ on running demands. The results of this study give coaches information on how kick-out strategies, passing strategies and defensive strategies impact on running performance.
\end{abstract}

\section{ARTICLE HISTORY}

Received 29 July 2017

Accepted 29 September 2017

\section{KEYWORDS}

Performance analysis; key performance indicators; physical demands; style of play

\section{Introduction}

Gaelic football is an amateur intermittent field sport that shares resemblances in movement demands with Australian rules football and soccer (Roe \& Malone, 2016). The sport is an invasion game where the aim is to outscore the opponent (Reilly \& Collins, 2008). It is played on a natural or synthetic pitch 130-145 $\mathrm{m}$ in length and 80-90 $\mathrm{m}$ in width between two teams of 15 players (Roe, Murphy, Gissane, \& Blake, 2016). In addition to a goalkeeper, teams will traditionally line out with three full backs, two half backs, two midfielders, three half forwards and three full forwards. The goal-posts in Gaelic football are akin to rugby, where there are two upright posts with a crossbar joining them at a height of $2.5 \mathrm{~m}$. During competition teams aim to score points and goals, with a goal being worth three points. After a point or goal is scored or when the ball goes wide of the goalposts, the goalkeeper 
resumes play with a kick-out taken off the ground. While in possession of the ball, players can move four steps before they must either bounce the ball or kick the ball off the foot and back into the hands, in an action called a solo. When passing to a teammate, players have the choice of performing a hand pass or a kick pass.

Although Gaelic football has an amateur status, the training regimes of elite players mirror that of professional athletes (Beasley, 2015; Shovlin, Roe, Malone, \& Collins, 2017) with players typically completing three to four training sessions per week plus a game at the weekend (Malone, Solan, \& Collins, 2017). Gaelic football is competed at club level (sub-elite) and inter-county level (elite). Inter-county teams are comprised of the best club players in each county. Currently, at inter-county level, teams participate in two major competitions; the National Football League (NFL) and the All Ireland football championship (Mangan \& Collins, 2016a). The NFL begins at the end of January and continues into April. The All Ireland football championship is a knockout competition that begins in May with the provincial championships, and culminates with the All Ireland final in September. Teams who are beaten during the provincial championship are awarded a second chance to qualify for the All Ireland quarter finals, via the All Ireland qualifiers, which run concurrent with the provincial championships.

During match-play, depending on playing position players typically cover between 6892 and $10621 \mathrm{~m}$, with $1331-2228 \mathrm{~m}$ of that being at high speed $\left(\geq 17 \mathrm{~km} \cdot \mathrm{h}^{-1}\right)$ (Malone, Solan, Collins, \& Doran, 2016a, 2016b). In terms of relative distance $\left(\mathrm{m} \cdot \mathrm{min}^{-1}\right)$, Gaelic football players have been shown to have similar worse case work rates (highest amount of distance covered in a minute) to Australian football players (Malone et al., 2017; Delaney, Thornton, Burgess, Dascombe, \& Duthie, 2017; Coutts et al., 2015). Anecdotally, running performance is used as a key performance indicator within Gaelic football. However, this mode of analysis is influenced by several contextual factors such as playing position (Collins, Solan, \& Doran, 2013), match half (Malone et al., 2016a), match quarter (Malone et al., 2017), opposition (Mangan et al., 2017a) and match outcome (Mangan et al., 2017b). While technical performance and running performance have been examined concurrently in sports such as cricket (Vickery et al., 2016), rugby sevens (Ross, Gill, \& Cronin, 2015), Australian football (Ryan, Coutts, Hocking, \& Kempton, 2017) and soccer (Barnes, Archer, Hogg, Bush, \& Bradley, 2014; Bradley et al., 2015; Rampinini, Impellizzeri, Castagna, Coutts, \& Wisløff, 2009), few attempts have been made to examine the interaction between technical and running performance and how the two influence each other (Filetti, Ruscello, D'Ottavio, \& Fanelli, 2017; Hoppe, Slomka, Baumgart, Weber, \& Freiwald, 2015). A recent study on 360 Serie A soccer players successfully showed a correlation between technical performance (technical efficiency index) and running performance (physical efficiency index) $(r=0.60)$ (Filetti et al., 2017). However, further research is warranted to examine how running performance links to technical performance and game events.

It has been suggested that an interaction between technical performance indicators and running performance may exist within Gaelic football since teams cover different amounts of total distance and high-speed distance (Mangan et al., 2017b). Anecdotal evidence suggests that teams who favour direct passing, run less distance, however, it is currently unclear if this is a linear relationship. Additionally, it has been reported that the closer the scoreline, the higher the running demands of players (Mangan et al., 2017b). Literature within soccer cohorts has shown that team formation (Bradley et al., 2011) and possession percentage (Bradley, Lago-Peñas, Rey, \& Gomez Diaz, 2013) can influence high-speed running 
$\left(\geq 19.8 \mathrm{~km} \mathrm{~h}^{-1}\right)$. Specifically, teams with higher percentage ball possession were observed to cover $31 \%$ more distance at high speed when contrast against low percentage ball possession teams. Within rugby league, players have been observed to cover greater distances when attacking compared to defending (Dave, Craig, Shayne, Ceri, \& Kevin, 2009). Wisbey and colleagues, (2010) have called for further investigations into the relationship between player movements and key performance indicators (KPIs) such as possessions, tackles and scoring, while Filetti et al. (2017) report that coaches and practitioners often question how parameters of running performance can be linked to technical and tactical factors. It's important for coaches to understand how their tactics (e.g. type of kick-out, preferred type of pass, area of defensive pressure) impact on the physical demands of their players. The primary aim of the current study was to assess the relationship between technical performance indicators and positional running demands of elite Gaelic football players. The secondary aim was to describe positional running demands and provide normative values for technical performance.

\section{Methods}

\subsection{Data collection}

Data were collected from four Gaelic football teams over a period of 3 years (2014-2016). The teams, who were all ranked in the top 15 out of 33 teams in Ireland (Mangan \& Collins, 2016a), were monitored across 52 matches. Ethical approval was awarded by the local institution's ethical committee. Informed consent was received from the participating teams and players before commencement of this research. Data collection began at the start of the NFL in 2014 and continued to the end of the All Ireland football championship of 2016. Only players with full 70-min data-sets were included in the analysis. In total, 432 individual full match data-sets were collected. During all games participants wore an individual GPS unit (VXsport, New Zealand, Issue: 330a) sampling at 4-Hz. The GPS unit (mass: 76 g; $48 \mathrm{~mm} \times 20 \mathrm{~mm} \times 87 \mathrm{~mm}$ ) was encased within a protective harness between the player's shoulder blades in the upper thoracic spine region, which ensured that players' range of movement in the upper limbs and torso was not restricted. The device was activated and satellite lock established for a minimum of $15 \mathrm{~min}$ prior to each game. The validity and reliability of the selected GPS receiver has been communicated previously (Buchheit et al., 2014; Malone, Doran, Collins, Morton, \& McRobert, 2014). The coefficient of variation $(\mathrm{CV})$ for the GPS receivers are less than $5 \%$ for total distance, low-speed distance, maximum speed and average speed, while high-speed distance has a CV of $8 \pm 2.5 \%$ (95\% CI) (Malone et al., 2014). All data were analysed retrospectively (VXSport View; Firmware 4.01.2.0). The data were then trimmed by time to ensure that only the time a player played for was recorded with warm up, cool down and half time periods removed. Once extracted, the data was transferred to a customised spreadsheet (Excel, Microsoft, Redmond, USA).

Match videos were obtained from a combination of television broadcasts of live games (RTÉ and TG4) and from the team's own recordings of games. Where possible, two different camera angles were used in the match coding and analysis stage. All matches were coded by the same individual who was familiar with the software. Matches were coded using SportsCode (SportsCode Elite V9, Sportstec, Warriewood, New South Wales, Australia) on a MacBook Pro using a customised match analysis template designed specifically for 
the current investigation. Once a full match was coded once, the game was then replayed to code tackles made by each team. The re-analysis was completed to add an extra layer of reliability to the analysis as all on the ball interactions were replayed, to remove any spurious errors made in the initial coding of the games. Following the completion of coding the first five games, three of those games were chosen at random to perform a test-retest reliability. The re-coding of games was completed 7 days following the original coding. Paired $t$-tests were used to examine test-retest reliability for each of the variables. Low percentage error was observed for all variables $(<2 \%)$.

\subsection{Variables and definitions}

Total distance $(\mathrm{m})$, high-speed distance $\left(\geq 17 \mathrm{~km} \mathrm{~h}^{-1} ; \mathrm{m}\right)$ and minutes spent on the pitch were noted for all players. Total distance was selected as it is a standard measure used in team sports, while high-speed distance $\left(\geq 17 \mathrm{~km} \mathrm{~h}^{-1} ; \mathrm{m}\right)$ has previously been reported in Gaelic football (Collins \& Doran, 2015; Malone et al., 2016a, 2016b). This differs to soccer where the high-speed threshold has been reported at $\left(\geq 16 \mathrm{~km} \mathrm{~h}^{-1}\right)$ (Randers et al., 2010) and $\left(\geq 18 \mathrm{~km} \mathrm{~h}^{-1}\right.$ ) (Mohr, Krustrup, \& Bangsbo, 2003). Table 1 shows the operational definitions provided for each technical variable coded during each match-play event. The teams who participated in this study are referred to throughout as the reference team, while the teams they faced are referred to as the opposition team.

Table 1. Technical variables and definitions.

\begin{tabular}{|c|c|}
\hline Technical variable & Definition \\
\hline Kick pass & $\begin{array}{l}\text { A clear striking action made with the foot in an attempt to transfer } \\
\text { the ball to a teammate }\end{array}$ \\
\hline Hand pass & $\begin{array}{l}\text { A clear striking action made with the hand/fist in an attempt to } \\
\text { transfer the ball to a teammate }\end{array}$ \\
\hline Successful pass & When a teammate gains possession of an attempted pass \\
\hline Unsuccessful pass & $\begin{array}{l}\text { When the attempted pass by an attacking player fails to reach a } \\
\text { teammate }\end{array}$ \\
\hline Score from play & A point or goal scored from open play \\
\hline Turnover & $\begin{array}{l}\text { When possession of the ball is transferred from one team to the } \\
\text { other (Inclusive of instances when the ball goes wide from a pass) }\end{array}$ \\
\hline Tackle & $\begin{array}{l}\text { If the defending player makes physical contact with the player in } \\
\text { possession or contact with the ball to win the ball or disrupt the } \\
\text { player in possession or as they attempt to strike the ball }\end{array}$ \\
\hline Foul & $\begin{array}{l}\text { When the referee blows the whistle for what they deem to be an act } \\
\text { of misconduct or a violation of the rules }\end{array}$ \\
\hline Defensive third & Area from the defending team's end line to their $45-\mathrm{m}$ line \\
\hline Middle third & The area between the two 45-m lines \\
\hline Attacking third & Area from the opposition 45-m line to the opposition's end line \\
\hline Kick-out & $\begin{array}{l}\text { After the ball has gone over the end line via the last touch of an } \\
\text { attacking player, the goalkeeper will restart the game by kicking } \\
\text { the ball into play }\end{array}$ \\
\hline Short kick-out & $\begin{array}{l}\text { When the kick-out from the goalkeeper lands inside their team's } \\
45-\mathrm{m} \text { line }\end{array}$ \\
\hline Long kick-out & $\begin{array}{l}\text { When the kick-out from the goalkeeper lands outside their team's } \\
45-\mathrm{m} \text { line }\end{array}$ \\
\hline Kick-out won & When the goalkeeper's team maintain possession of the ball \\
\hline Kick-out lost & $\begin{array}{l}\text { When the opposition team gain possession of the ball following a } \\
\text { kick-out }\end{array}$ \\
\hline Possession & When one team have control of the ball \\
\hline Time in possession & $\begin{array}{l}\text { The amount of time that a team have possession of the ball whilst it } \\
\text { is in play }\end{array}$ \\
\hline Defensive actions & The number of fouls + turnovers + tackles per pitch third \\
\hline
\end{tabular}




\subsection{Statistical analysis}

All data were anonymised before analysis to ensure the confidentiality of the participants and teams involved. Assumptions of normality were assessed before commencement of the statistical analysis. The data was deemed to be normally distributed. Statistical analyses were carried out in SPSS for Mac (V24.0, SPSS Inc., Chicago, Illinois, USA). All data were split based on playing position (full back, $n=104$; half back, $n=108$; midfield, $n=56$; half forward, $n=86$; full forward, $n=78$ ). Means and standard deviations were calculated to summarise the data. A one-way between-groups analysis of variance (ANOVA) was used to compare total distance and high-speed distance across positions. Pearson's product moment correlations $(r)$ were used to examine the correlations between total distance and highspeed distance and the selected technical variables. Statistical significance was accepted at $p \leq 0.05$. Qualitative interpretations of the correlation coefficients as defined by Cohen (1992) were applied to the current data-set (0-0.09 trivial; 0.1-0.29 small; 0.3-0.49 medium and $>0.5$ large). Comparisons between technical performance indicators (e.g. number of long kick-outs versus number of short kick-outs) were examined using effect sizes $(d)$ and reported qualitatively using benchmarks set by Hopkins (2002) (0-0.19 trivial; 0.2-0.59, small; 0.6-1.19, moderate and 1.2-2.0, large).

\section{Results}

\subsection{Positional running performance}

Midfielders, half backs and half forwards differed significantly to full backs and full forwards for total distance $(p \leq 0.001)$ and high-speed distance $(p \leq 0.001)$. Midfielders also covered significantly more total distance $(p \leq 0.001)$ and high-speed distance $(p=0.010)$ than half backs. Midfielders covered the greatest volume of total distance $(10,245 \pm 1972 \mathrm{~m})$, followed by half forwards $(9464 \pm 1612 \mathrm{~m})$, half backs $(8758 \pm 1543 \mathrm{~m})$, full forwards $(7766 \pm 2173 \mathrm{~m})$ and full backs $(7310 \pm 1163 \mathrm{~m})$. A similar hierarchal trend was evident for high-speed distance with midfielders running the most distance $(1921 \pm 719 \mathrm{~m})$, followed by half forwards $(1780 \pm 507 \mathrm{~m})$ and half backs $(1780 \pm 507 \mathrm{~m})$, however, full backs covered greater high-speed distance $(1404 \pm 533 \mathrm{~m})$ than full forwards $(1248 \pm 564 \mathrm{~m})$.

\subsection{Kick-outs}

Overall teams kicked the ball short $30 \pm 20 \%$ of the time, winning $92 \pm 19 \%$ of short kickouts. Of the $70 \pm 20 \%$ of kick-outs kicked long, teams retained possession just $56 \pm 13 \%$ of the time. A large difference was evident between the percentage of short kick-outs and the percentage of long kick-outs $(d=1.95)$. A similarly large difference was observed between the success rate of kick-outs $(d=1.64)$. Table 2 shows the correlations between kick-out type and success with total distance and high-speed distance. It is evident that a higher percentage of short kick-outs results in players running greater total and high-speed distance. Winning a high percentage of one's own kick-outs has small effects in increasing running demands while winning a high percentage of the opposition's kick-outs has the opposite effect on running demands. 
Table 2. The kick-out type and kick-out success in relation to running performance.

\begin{tabular}{|c|c|c|c|c|c|c|c|c|}
\hline \multirow[b]{2}{*}{ Position } & \multicolumn{4}{|c|}{ Total distance (m) } & \multicolumn{4}{|c|}{ High-speed distance (m) } \\
\hline & $\begin{array}{l}\text { Own } \\
\text { kick-outs } \\
\text { won } \\
(\%)\end{array}$ & $\begin{array}{l}\text { Opposition } \\
\text { kick-outs } \\
\text { won } \\
(\%)\end{array}$ & $\begin{array}{l}\text { Kick-outs } \\
\text { taken } \\
\text { short } \\
(\%)\end{array}$ & $\begin{array}{l}\text { Kick-outs } \\
\text { taken } \\
\text { short by } \\
\text { opposition } \\
(\%)\end{array}$ & $\begin{array}{l}\text { Own } \\
\text { kick-outs } \\
\text { won } \\
(\%)\end{array}$ & $\begin{array}{l}\text { Opposition } \\
\text { kick-outs } \\
\text { won } \\
(\%)\end{array}$ & $\begin{array}{l}\text { Kick-outs } \\
\text { taken } \\
\text { short } \\
(\%)\end{array}$ & $\begin{array}{l}\text { Kick-outs } \\
\text { taken } \\
\text { short by } \\
\text { opposition } \\
(\%)\end{array}$ \\
\hline \multicolumn{9}{|l|}{ Full back } \\
\hline$r$ & .059 & -.192 & $.235^{*}$ & $0.196^{*}$ & .035 & -.154 & .152 & .187 \\
\hline$p$ & 0.549 & 0.051 & 0.016 & 0.047 & 0.722 & 0.118 & 0.123 & 0.057 \\
\hline $\begin{array}{l}\text { Effect size } \\
\text { Half back }\end{array}$ & Trivial & Small & Small & Small & Trivial & Small & Small & Small \\
\hline$r$ & $.233^{*}$ & -.183 & $.311^{*}$ & $.301^{*}$ & .179 & -.174 & $.334^{*}$ & $.224^{*}$ \\
\hline$p$ & 0.015 & 0.058 & 0.001 & 0.002 & 0.063 & 0.071 & 0.000 & 0.02 \\
\hline $\begin{array}{l}\text { Effect size } \\
\text { Midfield }\end{array}$ & Small & Small & Medium & Medium & Small & Small & Medium & Small \\
\hline r & $.287^{*}$ & $-.279^{*}$ & $.431^{*}$ & $.367^{*}$ & .263 & -.257 & $.401^{*}$ & $.343^{*}$ \\
\hline$p$ & 0.032 & 0.038 & 0.001 & 0.005 & 0.050 & 0.056 & 0.002 & 0.01 \\
\hline $\begin{array}{l}\text { Effect size } \\
\text { Halfforward }\end{array}$ & Small & Small & Medium & Medium & Small & Small & Medium & Medium \\
\hline$r$ & .205 & -.196 & $.372^{*}$ & $0.296^{*}$ & .162 & -.189 & $.376^{*}$ & $.236^{*}$ \\
\hline$p$ & 0.059 & 0.071 & 0.000 & 0.006 & 0.136 & 0.082 & 0.000 & 0.028 \\
\hline $\begin{array}{l}\text { Effect size } \\
\text { Full forward }\end{array}$ & Small & Small & Medium & Small & Small & Small & Medium & Small \\
\hline$r$ & .138 & -.211 & $.232^{*}$ & $.324^{*}$ & .093 & -.176 & .146 & $.253^{*}$ \\
\hline$p$ & 0.230 & 0.063 & 0.041 & 0.004 & 0.416 & 0.123 & 0.202 & 0.026 \\
\hline Effect size & Small & Small & Small & Medium & Trivial & Small & Small & Small \\
\hline
\end{tabular}

*significant correlation at 0.05 level.

\subsection{Attacking play}

Teams chose to hand pass the ball rather than kick pass on $70 \pm 7 \%$ of occasions with a success rate of $96.66 \pm 1.55 \%$. When players elected to kick pass the ball (30 $\pm 7 \%$ of the time), they were successful $79 \pm 13 \%$ of the time. A large difference was noted between the percentage of hand passes and the percentage of kick passes $(d=6.07)$. There was a large difference in the success percentage of the different types of pass $(d=1.93)$. Table 3 displays the correlations for passing type and passing success with total distance and high-speed distance. A higher preference for hand passes over kick passes had small effect in increasing the total distance and high-speed distance that players ran.

The total time that the ball was in play had significant small to medium correlation with total distance and high-speed distance for all positions (Table 4). Teams had an average of $69 \pm 8$ possessions per game, lasting $17 \pm 3$ s. Table 4 shows that as ball in play time and opposition possession time increased, so too did the amount of total distance and highspeed distance covered by reference team players.

The average number of shots taken per team was $27 \pm 5$, which meant that possessions ended in a shot $41 \pm 12 \%$ of the time. The majority of shots were taken from play $(75 \pm 11 \%)$. Table 5 shows that the number of shots per possession of the opposition team (how attacking the opposition were) had a small positive effect in increasing high-speed distance covered by all players on the reference team. 
Table 3. Passing type and passing success vs. running performance.

\begin{tabular}{|c|c|c|c|c|c|c|c|c|}
\hline \multirow[b]{2}{*}{ Position } & \multicolumn{4}{|c|}{ Total distance $(\mathrm{m})$} & \multicolumn{4}{|c|}{ High-speed distance (m) } \\
\hline & $\begin{array}{l}\text { Percentage } \\
\text { of passes } \\
\text { that are } \\
\text { hand passes } \\
\text { reference } \\
\text { team }\end{array}$ & $\begin{array}{l}\text { Percentage } \\
\text { of passes } \\
\text { that are } \\
\text { hand passes } \\
\text { opposition }\end{array}$ & $\begin{array}{l}\text { Percent- } \\
\text { age pass } \\
\text { success } \\
\text { reference } \\
\text { team }\end{array}$ & $\begin{array}{l}\text { Percent- } \\
\text { age pass } \\
\text { success } \\
\text { opposi- } \\
\text { tion }\end{array}$ & $\begin{array}{l}\text { Percentage } \\
\text { of passes } \\
\text { that are hand } \\
\text { passes refer- } \\
\text { ence team }\end{array}$ & $\begin{array}{c}\text { Percentage } \\
\text { of passes } \\
\text { that are } \\
\text { hand passes } \\
\text { opposition }\end{array}$ & $\begin{array}{l}\text { Percent- } \\
\text { age pass } \\
\text { success } \\
\text { reference } \\
\text { team }\end{array}$ & $\begin{array}{l}\text { Percent- } \\
\text { age pass } \\
\text { success } \\
\text { opposi- } \\
\text { tion }\end{array}$ \\
\hline Full back & & & & & & & & \\
\hline$r$ & $.219 *$ & 0.083 & 0.133 & 0.128 & $.265^{*}$ & 0.021 & 0.094 & 0.168 \\
\hline$p$ & 0.026 & 0.401 & 0.178 & 0.195 & 0.007 & 0.832 & 0.342 & 0.088 \\
\hline $\begin{array}{l}\text { Effect size } \\
\text { Half back }\end{array}$ & Small & Trivial & Small & Small & Small & Trivial & Trivial & Small \\
\hline$r$ & 0.136 & 0.104 & -0.001 & 0.184 & $.193^{*}$ & 0.091 & 0.048 & 0.129 \\
\hline$p$ & 0.16 & 0.286 & 0.991 & 0.056 & 0.16 & 0.35 & 0.622 & 0.185 \\
\hline $\begin{array}{l}\text { Effect size } \\
\text { Midfield }\end{array}$ & Small & Small & Trivial & Small & Small & Trivial & Trivial & Small \\
\hline$r$ & $.280^{*}$ & 0.117 & 0.096 & 0.171 & $.275^{*}$ & 0.017 & 0.095 & 0.048 \\
\hline$p$ & 0.037 & 0.391 & 0.482 & 0.209 & 0.04 & 0.902 & 0.486 & 0.728 \\
\hline $\begin{array}{l}\text { Effect size } \\
\text { Half forward }\end{array}$ & Small & Small & Trivial & Small & Small & Trivial & Trivial & Trivial \\
\hline$r$ & 0.161 & 0.096 & 0.096 & 0.104 & 0.177 & 0.03 & 0.137 & 0.066 \\
\hline$p$ & 0.139 & 0.377 & 0.381 & 0.342 & 0.102 & 0.78 & 0.208 & 0.548 \\
\hline $\begin{array}{l}\text { Effect size } \\
\text { Full forward }\end{array}$ & Small & Trivial & Trivial & Small & Small & Trivial & Small & Trivial \\
\hline$r$ & 0.216 & 0.012 & 0.105 & 0.129 & 0.188 & -0.044 & 0.092 & 0.118 \\
\hline$p$ & 0.057 & 0.917 & 0.362 & 0.216 & 0.099 & 0.702 & 0.423 & 0.303 \\
\hline Effect size & Small & Trivial & Small & Small & Small & Trivial & Trivial & Small \\
\hline
\end{tabular}

*significant correlation at 0.05 level.

\subsection{Defensive play}

The greatest number of defensive actions happened in the defensive third $(65 \pm 27$, followed by the midfield third $(55 \pm 22)$ and finally the attacking third $(16 \pm 7)$. Teams committed $21 \pm 5$ fouls per game, with $49 \pm 13 \%$ of these coming in the middle third of the pitch. Table 5 displays the correlations between defensive actions per pitch third and running performance. Significant small to medium negative correlations are evident between the number of fouls committed in the middle third by the reference team and running performance in full backs, half backs, midfielders and half forwards (see Table 6).

\section{Discussion}

The current study aimed to assess whether technical performance indicators relate to positional running demands of elite Gaelic football players and additionally to describe positional running demands and provide normative values for technical performance. Positional running demands in terms of total distance are higher than figures previously reported, however, high-speed distance figures are lower (Malone et al., 2016a). Given the size of the current data-set, our data may provide a more comprehensive indication of match play running performance when compared to previous literature (Collins et al., 2013; Malone et al., 2016a).We have shown that small to medium correlations exist between technical performance indicators and positional running performance. The correlations appear to be position-specific. Total time in play, percentage of kick-outs taken short and opposition time in possession showed the greatest positive correlations with total distance and high-speed 


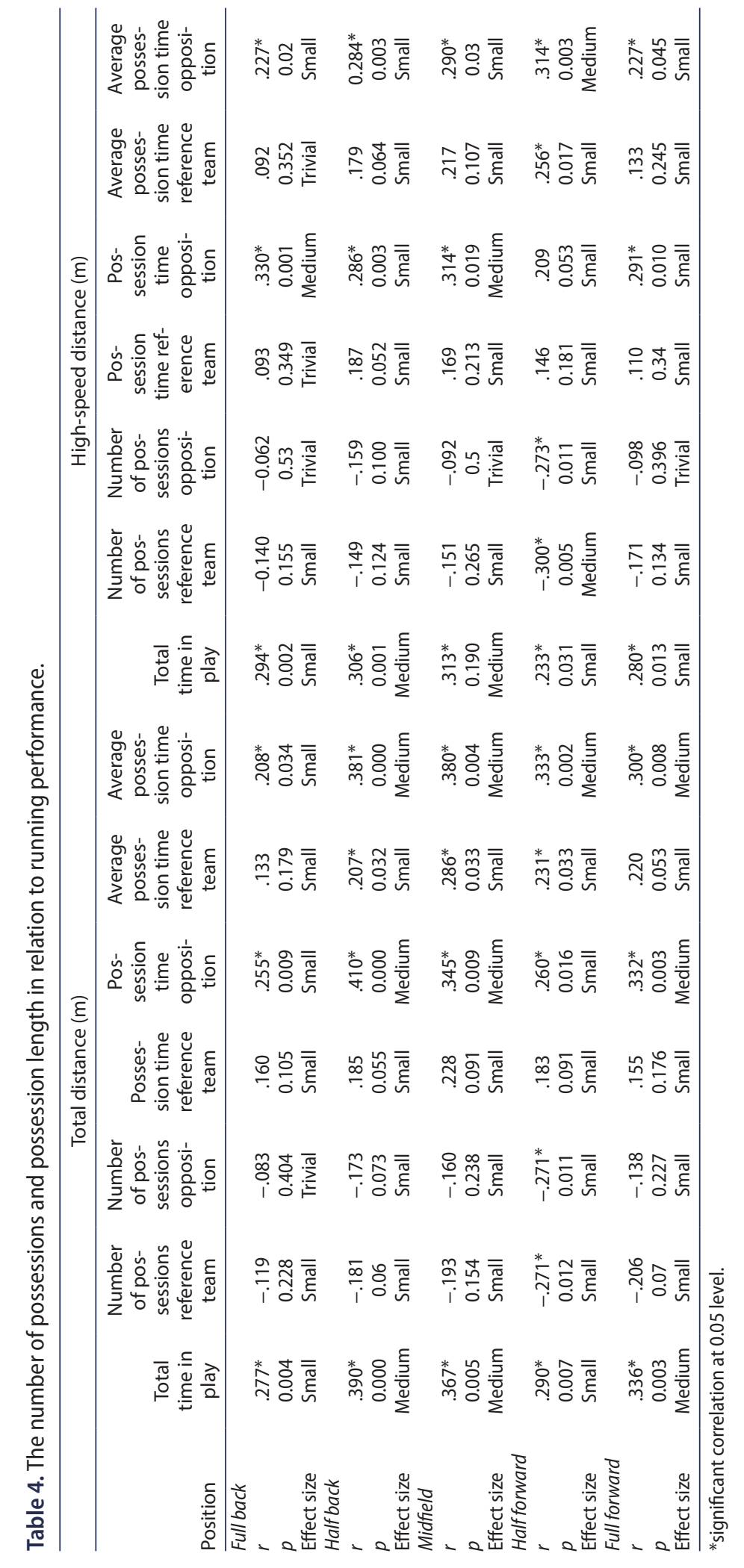




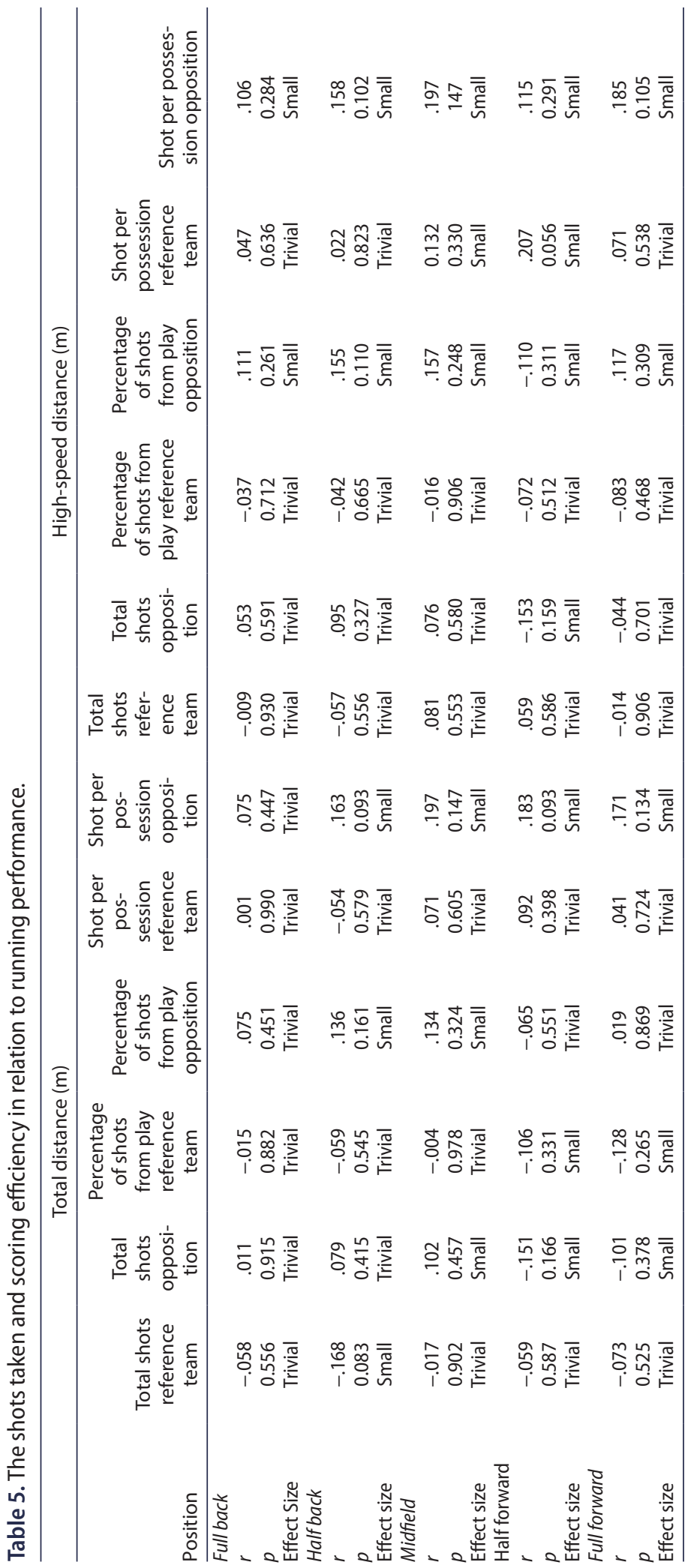




\begin{tabular}{|c|c|c|c|c|c|}
\hline 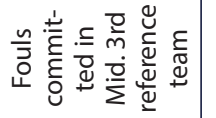 & 苫 & 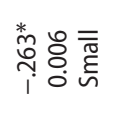 & 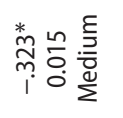 & 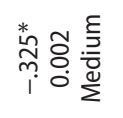 & o̊ \\
\hline 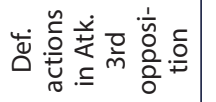 & 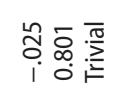 & 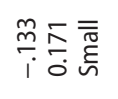 & $\underset{i}{\bar{\sigma}} \cong \stackrel{\overline{\bar{\sigma}}}{\underline{E}}$ & 范可. & 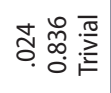 \\
\hline 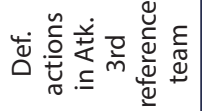 & 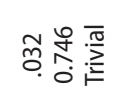 & 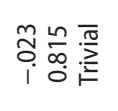 & 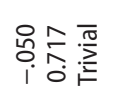 & 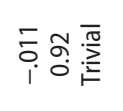 & 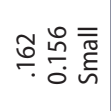 \\
\hline 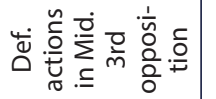 & 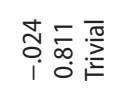 & 合兑: & 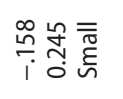 & 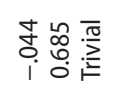 & 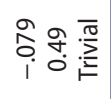 \\
\hline 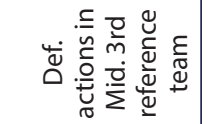 & 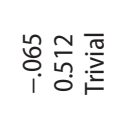 & 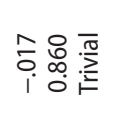 & 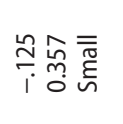 & 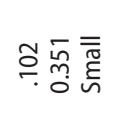 & 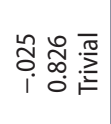 \\
\hline 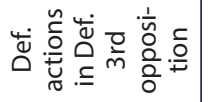 & 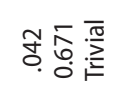 & 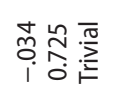 & 옹ㅎํ & 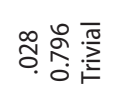 & б̄ \\
\hline 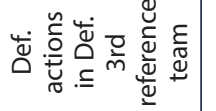 & \begin{tabular}{l} 
苂 $\frac{0}{\bar{\sigma}} \overline{\bar{\sigma}}$ \\
\hdashline \\
\hdashline
\end{tabular} & 必芯 & 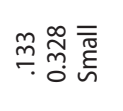 & 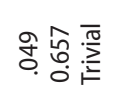 & 光垥 \\
\hline 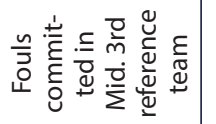 & 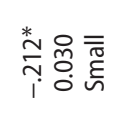 & 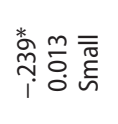 & 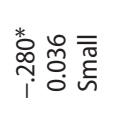 & 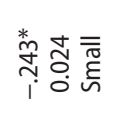 & ô \\
\hline 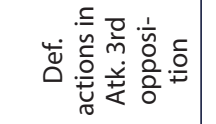 & 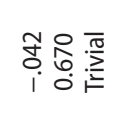 & 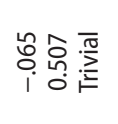 & 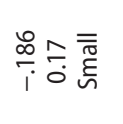 & 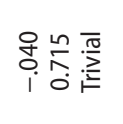 & 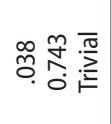 \\
\hline 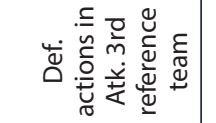 & 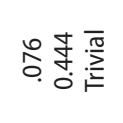 & 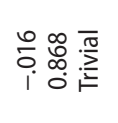 & 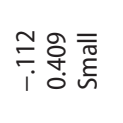 & $\bar{m}$ o & 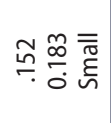 \\
\hline 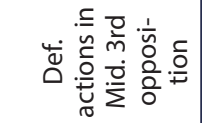 & 饮员务 & 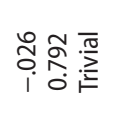 & 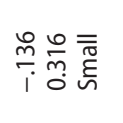 & 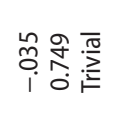 & 吕高高: \\
\hline 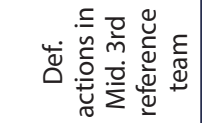 & 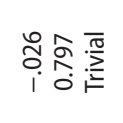 & 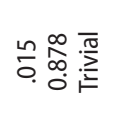 & 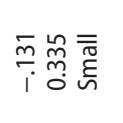 & 苍管 & 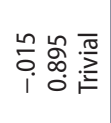 \\
\hline 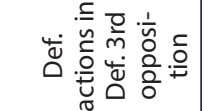 & 苔苔苔: & 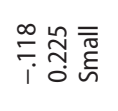 & 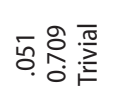 & $\begin{array}{l}\text { o } \\
\text { ơ } \\
i_{1}\end{array}$ & 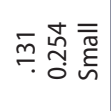 \\
\hline 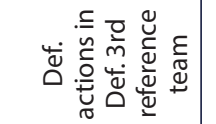 & 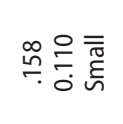 & 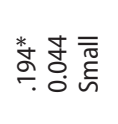 & 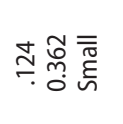 & môn & 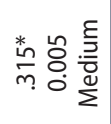 \\
\hline
\end{tabular}


distance. A high number of fouls committed in the middle third by the reference teams had a small-medium effect in terms of reducing the total distance and high-speed distance ran by backs, midfielders and half forwards.

Kick-outs have been a major area of discussion for Gaelic football coaches in recent years, especially with the introduction of "the mark" in 2017, an initiative to encourage teams to kick the ball long from restarts (Gaelic Athletic Association, 2017). Our results show that winning your own kick-out has a small effect $(r=.162-.287)$ in terms of increasing the amount of total distance and high-speed distance covered by half backs, midfielders and half forwards (Table 2). At the opposite end of the pitch, winning the opposition's kick-outs was found to have a small effect ( $r=-.154$ to -.279 ) in reducing the amount of total distance and high-speed distance covered by all positions. Our findings appear to follow a logical trend given that the further advanced up the pitch a team wins the ball, the less distance they have to travel to create a scoring opportunity. Interestingly, we observed that percentage of kick-outs taken short by the reference team $(r=.146-.431)$ and the opposition team $(r=.187-.367)$ have small to medium effects in increasing total distance and high-speed distance. A possible explanation for this is that when kick-outs are taken short, teams are further away from the opposition goal with more opposition players to get past to get into a scoring position. Within Australian football an analysis of kick-ins showed that $49 \%$ are kicked over 50-m, while 21\% are kicked under 25-m (Appleby \& Dawson, 2002), with the retention rate for long kick-ins $29 \%$, in comparison to $93.4 \%$ for short kick-ins. Our findings show much greater retention rates for long kick-outs (56\% vs. 29\%) but similar retention rates for short kick-outs (92\% vs. 93\%).

From our results, it is evident that teams prefer the use of hand passes over kick passes. This is likely to do with the lower risk of hand passes and the greater success rate as opposed to kick passes (97\% vs. $79 \%$ ). Types of passes have not previously been reported before in Gaelic football. Hand passing creates greater opportunity for midfielders and half-forwards to provide support and also greater time for forwards to make decisive runs (Bradley \& O'Donoghue, 2011). Our data show that a high percentage of passing success by the opposition has a small effect in increasing total distance covered by the reference team. This extra exertion is perhaps a contributing factor to the fact that, as the number of passes increase in a counter-attack, so too does the chance of scoring, while the chances of a turnover are decreased (Bradley \& O’Donoghue, 2011).

The current data demonstrate that the longer the ball is in play, the greater amount of total distance and high-speed distance that players will run. Interestingly, findings in rugby league show that the longer the ball is in play, the less relative distance players will run (Gabbett, 2015). Further work is needed to assess whether ball in play time impacts negatively on relative distances in Gaelic football. Stronger positive correlations were observed between distances and opposition possession time than distances and the reference team possession time (Table 4). This suggests that players work harder when out of possession rather than when they are in possession of the ball, a trend also evident in rugby league (Gabbett, Polley, Dwyer, Kearney, \& Corvo, 2014). Time in possession is perhaps a performance indicator that can be coded in real time during matches to give coaches a surrogate for players' physical exertion during match-play as they are deciding on making substitutions. Interestingly, it was found that performance indicators relating to shots only had trivial to small effects on running distances. This may be explained by the fact that a proportion of shots taken in Gaelic football come after attacks that last less than $10 \mathrm{~s}$, while other shots come after attacks 
lasting far greater than $20 \mathrm{~s}$ (Mangan \& Collins, 2016b). This unpredictability therefore makes it difficult to relate shot-based performance indicators to running performance.

The total number of defensive actions in the defensive third by the reference team surprisingly had the greatest positive effect on distance for the reference team's full forwards. This is perhaps a reflection that when teams pull players back to defend in their defensive third, there is a greater responsibility for full forwards to fill the voids left by half forwards and midfielders. The number of fouls committed in the middle third by the reference team had small to medium negative effects on total distance and high-speed distance for all positions apart from full forwards. By breaking up opposition possessions with fouls, players are slowing the game down, with this impacting the degree to which players complete distance at high speed. It remains to be seen whether a large number of fouls in the middle third influences success in Gaelic football, however, we have observed that it relates to a reduction in running demands, which could potentially have an influence on the result (Mangan et al., 2017b).

A limitation of this study is that only one contextual factor (playing position) was used to divide the data for analysis. A review of the factors that influence running performance in soccer states that no study can control for all extraneous factors but this should not deter researchers from exploring the area with the potential for at least creating a hierarchy for these factors (time of season, pitch size, team quality, match importance, fitness levels, weather) (Paul, Bradley, \& Nassis, 2015). Similarly, playing experience and tactical awareness could potentially influence decision-making when it comes to conscious movements. More robust studies with large samples are needed to perform multivariate statistical analyses of these factors (Paul et al., 2015). The current investigation is one of the largest studies relating to Gaelic football match demands to date yet the sample size is not sufficient to perform a full multivariate analysis for contextual factors. Another limitation that was evident when watching broadcast coverage of games was that in some instances, replays would be shown when the ball was in play so some events may have been missed in the coding process. While a sample size of 4 teams gives a breadth in the representation of elite teams, it is likely that differences exist between the teams in terms of physical and technical performance (Mangan et al., 2017b). A further limitation of this research is that in 2017 the rules for kick-outs have changed with the introduction of the mark (Gaelic Athletic Association, 2017). Consequently, the findings of this research relating to kick-outs may not be a true reflection of the current game. Future research should be conducted to investigate the effect of these rule changes.

\section{Conclusion}

The current study is the first to examine the relationship between technical performance indicators and running performance measures in Gaelic football. The findings demonstrate that some technical performance indicators influence running performance. The type of opposition kick-out and opposition possession length was found to have an effect on position specific running performance. This information may be useful to teams in terms of planning training load when playing against teams with different styles of play. By committing fouls in the midfield area, players are reducing the amount of distance that they are required to run while also giving themselves greater time to get back in position. Further research is needed to examine whether there is an advantage to fouling high up 
the field, in terms of winning the game. The areas where defensive actions are carried out have position-specific effects on running demands. Coaches should consider the association between positional running performance and technical outputs when designing training protocols and deciding on specific game tactics.

\section{Acknowledgements}

The authors would like to thank each of the teams and all the players who participated in this research.

\section{Disclosure statement}

No potential conflict of interest was reported by the authors.

\section{Funding}

No external sources of funding were provided for this research.

\section{ORCID}

Kieran Collins (D) http://orcid.org/0000-0003-1653-2071

\section{References}

Appleby, B., \& Dawson, B. (2002). Video analysis of selected game activities in Australian rules football. Journal of Science and Medicine in Sport, 5(2), 129-142. Retrieved from http://www.ncbi. nlm.nih.gov/pubmed/12188085

Barnes, C., Archer, D. T., Hogg, B., Bush, M., \& Bradley, P. S. (2014). The evolution of physical and technical performance parameters in the english premier league. International Journal of Sports Medicine, 35, 1095-1100. doi:10.1055/s-0034-1375695

Beasley, K. J. (2015). Nutrition and Gaelic football: Review, recommendations, and future considerations. International Journal of Sport Nutrition and Exercise Metabolism, 25(1), 1-13. doi:10.1123/ijsnem.2013-0214

Bradley, J., \& O’Donoghue, P. (2011). Counterattacks in elite Gaelic football competition. International Journal of Performance Analysis in Sport, 11(1), 159-170. Retrieved from http://www.ingentaconnect. com/content/uwic/ujpa/2011/00000011/00000001/art00015

Bradley, P. S., Archer, D. T., Hogg, B., Schuth, G., Bush, M., Carling, C., \& Barnes, C. (2015). Tierspecific evolution of match performance characteristics in the English Premier League: It's getting tougher at the top. Journal of Sports Sciences, 414(September), 1-8. doi:10.1080/02640414.2015. 1082614

Bradley, P. S., Carling, C., Archer, D., Roberts, J., Dodds, A., Di Mascio, M., ... Krustrup, P. (2011). The effect of playing formation on high-intensity running and technical profiles in English FA Premier League soccer matches. Journal of Sports Sciences, 29(8), 821-830. doi:10.1080/0264041 4.2011.561868

Bradley, P. S., Lago-Peñas, C., Rey, E., \& Gomez Diaz, A. (2013). The effect of high and low percentage ball possession on physical and technical profiles in English FA Premier League soccer matches. Journal of Sports Sciences, 31(12), 1261-1270. doi:10.1080/02640414.2013.786185

Buchheit, M., Allen, A., Poon, T. K., Modonutti, M., Gregson, W., \& Di Salvo, V. (2014). Integrating different tracking systems in football: Multiple camera semi-automatic system, local position measurement and GPS technologies. Journal of Sports Sciences, 32(20), 1844-1857. doi:10.1080/ 02640414.2014 .942687 
Cohen, J. (1992). A power primer. Psychological Bulletin, 112(1), 155-159. doi:10.1037/00332909.112.1.155

Collins, D. K., \& Doran, D. (2015, May 20-23). The performance profile and physical demands of elite Gaelic football. In 8th World Congress of Science \& Football, Copenhagen.

Collins, K., Solan, B., \& Doran, D. A. (2013). A preliminary investigation into high-intensity activity during elite Gaelic football. Journal of Sports Therapy, 1, 10.

Coutts, A. J., Kempton, T., Sullivan, C., Bilsborough, J., Cordy, J., \& Rampinini, E. (2015). Metabolic power and energetic costs of professional Australian football match-play. Journal of Science and Medicine in Sport, 18(2), 219-224. doi:10.1016/j.jsams.2014.02.003

Dave, S., Craig, T., Shayne, H., Ceri, N., \& Kevin, L. (2009). Semi-automated time-motion analysis of senior elite rugby league. International Journal of Performance Analysis in Sport, 9(1), 47-59. Retrieved from http://www.ingentaconnect.com/content/uwic/ujpa/2009/00000009/00000001/ art00005? crawler=true

Delaney, J. A., Thornton, H. R., Burgess, D. J., Dascombe, B. J., \& Duthie, G. M. (2017). Durationspecific running intensities of Australian Football match-play. Journal of Science and Medicine in Sport, 20(7), 689-694. Retrieved from https://doi.org/10.1016/j.jsams.2016.11.009

Filetti, C., Ruscello, B., D’Ottavio, S., \& Fanelli, V. (2017). A study of relationships among technical, tactical, physical parameters and final outcomes in elite soccer matches as analyzed by a semiautomatic video tracking system. Perceptual and Motor Skills, 124(3): 601-620, 3151251769290 doi:10.1177/0031512517692904

Gabbett, T. J. (2015). Influence of ball-in-play time on the activity profiles of rugby league match-play. Journal of Strength and Conditioning Research, 29(3), 716-721. doi:10.1519/JSC.0000000000000446

Gabbett, T. J., Polley, C., Dwyer, D. B., Kearney, S., \& Corvo, A. (2014). Influence of field position and phase of play on the physical demands of match-play in professional rugby league forwards. Journal of Science and Medicine in Sport, 17(5), 556-561. doi:10.1016/j.jsams.2013.08.002

Gaelic Athletic Association. (2017). Gaelic athletic association official guide. Retrieved 17 July 2017, from http://www.gaa.ie/mm/Document/TheGAA/RulesandRegulations/13/79/78/ GAAOfficialGuide2017_Part1_Neutral.pdf

Hopkins, W. G. (2002). A scale of magnitudes for effect statistics. Sportscience, 5, 1-7.

Hoppe, M., Slomka, M., Baumgart, C., Weber, H., \& Freiwald, J. (2015). Match running performance and success across a season in german bundesliga soccer teams. International Journal of Sports Medicine, 36(7), 563-566. doi:10.1055/s-0034-1398578

Malone, S., Doran, D., Collins, K., Morton, J., \& McRobert, A. (2014). Accuracy and reliability of VXsport global positioning system in intermittent activity. Proceedings of the 19th Annual Congress of the European College of Sport Science. Amsterdam.

Malone, S., Solan, B., \& Collins, K. (2017). The running performance profile of elite Gaelic football match-play. Journal of Strength \& Conditioning Research, 31(1), 1-25. doi:10.1519/ JSC. 0000000000001477

Malone, S., Solan, B., Collins, K., \& Doran, D. (2016a). Positional match running performance of elite Gaelic football. Journal of Strength and Conditioning Research, 30(8), 2292-2298. doi:10.1519/ JSC.0000000000001309

Malone, S., Solan, B., Collins, K., \& Doran, D. (2016b). The metabolic power and energetic demands of elite Gaelic football match play. The Journal of Sports Medince and Physical Fitness, 57, 1-20.

Mangan, S., \& Collins, K. (2016a). A rating system for Gaelic football teams: Factors that influence success. International Journal of Computer Science in Sport, 15(2), 78-90. doi:10.1515/ijcss-2016-0006

Mangan, S., \& Collins, K. (2016b). An analysis of shooting attempts in inter county Gaelic football. Carlow: International Society of Performance Analysis of Sport 6th International Workshop book of abstracts. Retrieved from http://www.itcarlow.ie/public/userfiles/files/ EDITEDPROGRAMMEMDH_KHv2.pdf

Mangan, S., Malone, S., Ryan, M., McGahan, J., O’Neill, C., Burns, C., ... Collins, K. (2017a). The effect of contextual factors on running performance in elite Gaelic football. In All Ireland Postgraduate Conference in Sport Sciences, Physical Activity and Physical Education.

Mangan, S., Malone, S., Ryan, M., McGahan, J., O’Neill, C., Burns, C., ... Collins, K. (2017b). The influence of match outcome on running performance in elite Gaelic football. Science and Medicine in Football, 1(3): 272-279. 
Mohr, M., Krustrup, P., \& Bangsbo, J. (2003). Match performance of high-standard soccer players with special reference to development of fatigue. Journal of Sports Sciences, 21, 519-528. doi:10.1080/0264041031000071182

Paul, D., Bradley, P., \& Nassis, G. (2015). Factors affecting match running performance of elite soccer players: Shedding some light on the complexity. International Journal of Sports Physiology and Performance, 10(4), 516-519. doi:10.1123/IJSPP.2015-0029

Rampinini, E., Impellizzeri, F. M., Castagna, C., Coutts, A. J., \& Wisløff, U. (2009). Technical performance during soccer matches of the Italian Serie A league: Effect of fatigue and competitive level. Journal of Science and Medicine in Sport, 12(1), 227-233. doi:10.1016/j.jsams.2007.10.002

Randers, M. B., Mujika, I., Hewitt, A., Santisteban, J., Bischoff, R., Solano, R., ... Mohr, M. (2010). Application of four different football match analysis systems: A comparative study. Journal of Sports Sciences, 28(2), 171-182. doi:10.1080/02640410903428525

Reilly, T., \& Collins, K. (2008). Science and the Gaelic sports: Gaelic football and hurling. European Journal of Sport Science, 8(5), 231-240. doi:10.1080/17461390802251851

Roe, M., \& Malone, S. (2016). Yo-yo intermittent recovery test performance in sub-elite Gaelic football players from under 13 to senior age group. The Journal of Strength and Conditioning Research, 30(11), 3187-3193. doi:10.1097/JSC.0000000000000227

Roe, M., Murphy, J. C., Gissane, C., \& Blake, C. (2016). Hamstring injuries in elite Gaelic football: An 8-year investigation to identify injury rates, time-loss patterns and players at increased risk. British Journal of Sports Medicine, bjsports-2016-096401. doi:10.1136/bjsports-2016-096401

Ross, A., Gill, N., \& Cronin, J. (2015). The match demands of international rugby sevens. Journal of Sports Sciences, 33(10), 1035-1041. doi:10.1080/02640414.2014.979858

Ryan, S., Coutts, A. J., Hocking, J., \& Kempton, T. (2017). Factors affecting match running performance in professional australian football. International Journal of Sports Physiology and Performance, 1-19, doi:10.1123/ijspp.2016-0586

Shovlin, A., Roe, M., Malone, S., \& Collins, K. (2017). The positional anthropometric and performance profile of elite Gaelic football players. Journal of Strength and Conditioning Research, 1, doi:10.1519/ JSC.0000000000002071

Vickery, W., Duffield, R., Crowther, R., Beakley, D., Blanch, P., \& Dascombe, B. J. (2016). Comparison of the physical and technical demands of cricket players during training and match-play. Journal of Strength and Conditioning Research, 1, doi:10.1519/JSC.0000000000001528

Wisbey, B., Montgomery, P. G., Pyne, D. B., \& Rattray, B. (2010). Quantifying movement demands of AFL football using GPS tracking. Journal of Science and Medicine in Sport, 13(5), 531-536. doi:10.1016/j.jsams.2009.09.002 